Corrigendum

\title{
Corrigendum to "Determinants of Mortality in Patients with Nosocomial Acinetobacter baumannii Bacteremia in Southwest China: A Five-Year Case-Control Study"
}

\author{
Shuangshuang Yang $\mathbb{D}$, Jide Sun, Xianan Wu, and Liping Zhang $\mathbb{D}$ \\ Department of Laboratory Medicine, The First Affiliated Hospital of Chongqing Medical University, No. 1, Youyi Road, \\ Yuzhong District, Chongqing 400016, China \\ Correspondence should be addressed to Liping Zhang; 1309898173@qq.com \\ Received 17 March 2019; Accepted 21 March 2019; Published 9 May 2019 \\ Copyright ( $) 2019$ Shuangshuang Yang et al. This is an open access article distributed under the Creative Commons Attribution \\ License, which permits unrestricted use, distribution, and reproduction in any medium, provided the original work is \\ properly cited.
}

In the article titled "Determinants of Mortality in Patients with Nosocomial Acinetobacter baumannii Bacteremia in Southwest China: A Five-Year Case-Control Study" [1], there was an error in the Acknowledgments section, as the funding details of the Chongqing Science and Technology Commission Grant (cstc2016jcyjA0769) was incorrect, and the correct number is (cstc2016jcyjA0248).

\section{References}

[1] S. Yang, J. Sun, X. Wu, and L. Zhang, "Determinants of Mortality in Patients with Nosocomial Acinetobacter baumannii Bacteremia in Southwest China: A Five-Year CaseControl Study," Canadian Journal of Infectious Diseases and Medical Microbiology, vol. 2018, Article ID 3150965, 9 pages, 2018. 


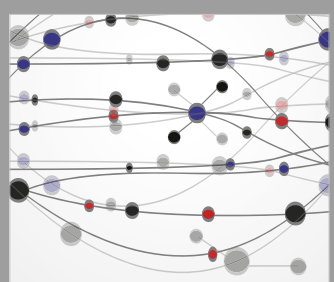

The Scientific World Journal
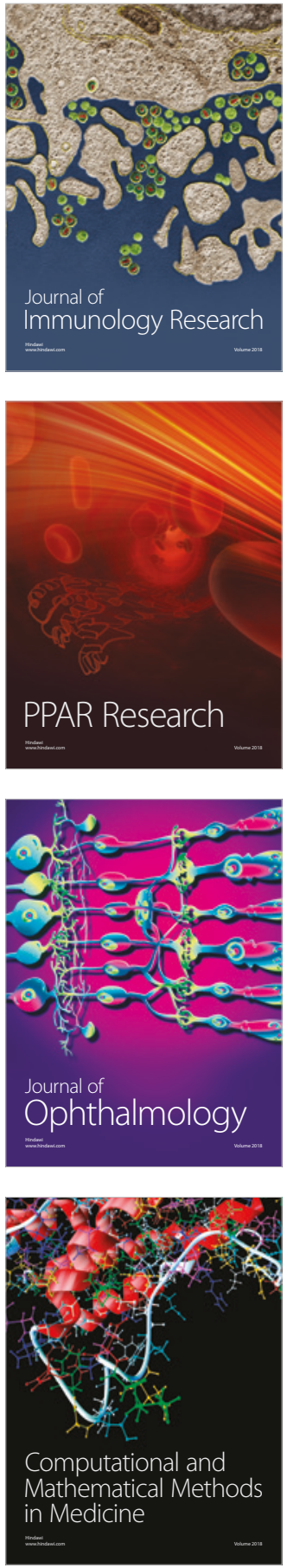

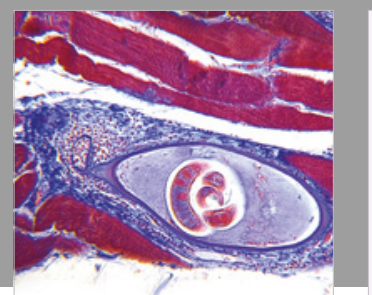

Gastroenterology Research and Practice

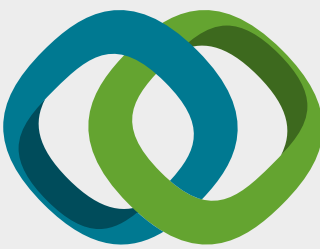

\section{Hindawi}

Submit your manuscripts at

www.hindawi.com
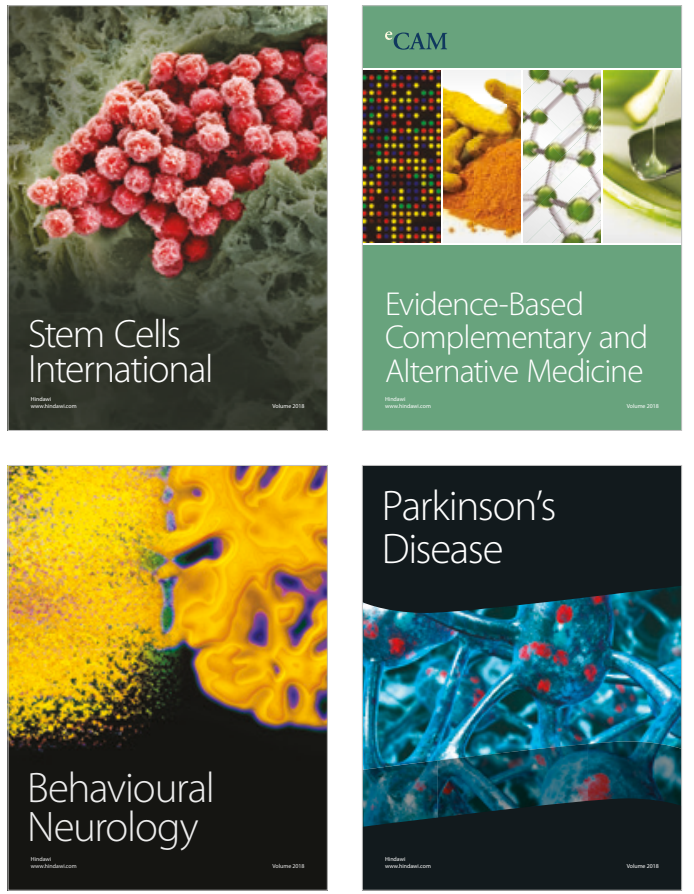

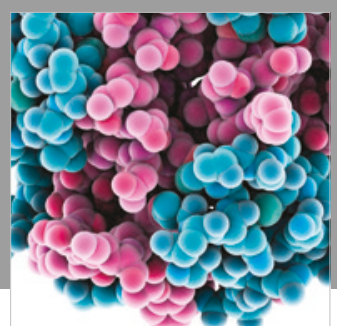

ournal of

Diabetes Research

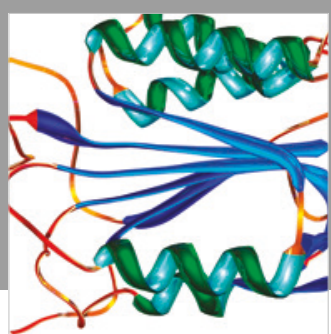

Disease Markers
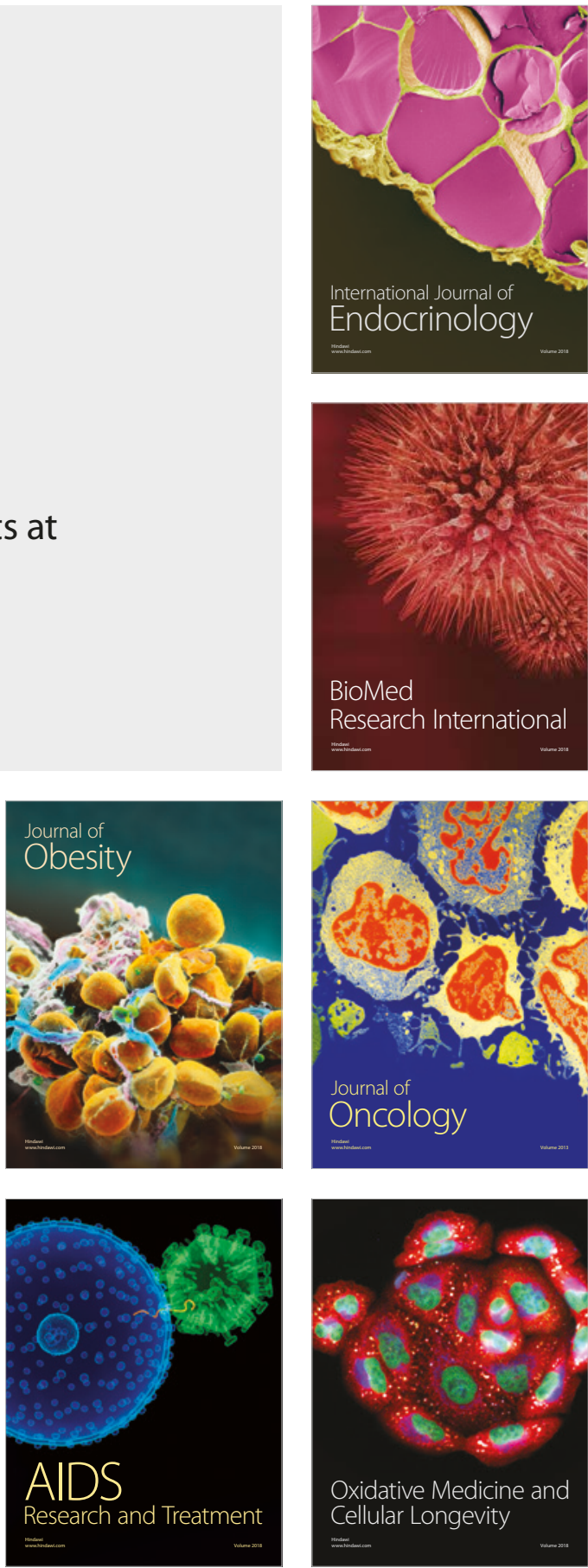